\title{
Production enhancement of the glycopeptide antibiotic A40926 produced by an engineered $\mathbf{N}$. gerenzanensis Icu1
}

\section{Bingyu Yan}

Liaocheng University

\section{Wen Gao}

Liaocheng University

Li Tian

Liaocheng University

\section{Shuai Wang}

Liaocheng University

Huijun Dong ( $\nabla$ donghuijun_747@163.com )

Liaocheng University https://orcid.org/0000-0002-6899-879X

\section{Research Article}

Keywords: A40926 ,N. gerenzanensis , Genetic engineering , Central composite design

Posted Date: July 21st, 2021

DOI: https://doi.org/10.21203/rs.3.rs-624980/v1

License: (c) (1) This work is licensed under a Creative Commons Attribution 4.0 International License. Read Full License 


\section{Abstract \\ Objective}

To enhance the production of A40926 by implementing a strategy of the combination of genetically engineered strain construction and medium optimization.

\section{Results}

The engineered strain of Nonomuraea gerenzanensis presented an increment of 30.6 percent in A40926 production compared with that of the parent strain. Subsequently, an assembling medium, which was defined as M9 medium and mainly comprised glucose, maltodextrin, soybean meal, peptone, L-valine, and other inorganic salts, was determined as the optimal medium among the tested nine media. The optimum concentration of medium components was glucose $10 \mathrm{~g} / \mathrm{l}$, maltodextrin $37.9 \mathrm{~g} / \mathrm{l}$, soybean meal $34.5 \mathrm{~g} / \mathrm{l}$, peptone $30.0 \mathrm{~g} / \mathrm{l}$, and L-valine $4.3 \mathrm{~g} / \mathrm{l}$, respectively. The optimized medium was verified experimentally, and A40926 yield increased significantly from $257 \mathrm{mg} / \mathrm{l}$ to $332 \mathrm{mg} / \mathrm{l}$, as compared to the non-optimized medium. The strategy brought a significant increase of A40926 yield by 65.2 percent.

\section{Conclusions}

The engineered mutant with the genetic attributes of the co-expression of the $d b v 3$ and $d b v 20$ genes and the deletion of the $d b v 23$ gene could obviously enhance the production of A40926. In addition, the optimization of medium was an effective and essential tool for the improvement of the secondary metabolites in Actinomyces.

\section{Introduction}

The antibiotic A40926 belongs to the teicoplanin family of glycopeptides antibiotics (GPAs), which remain a tool of last resort for treating resistant, "superbug" bacterial infections in clinic (Yim et al. 2014). It is the precursor of dalbavancin, a second-generation glycopeptide, and consists of a heptapeptide skeleton, two sugar residues, two chlorine atoms, and an acyl chain (Marschall et al. 2019). The $d b v$ (from dalbavancin) cluster, is involved in the biosynthesis of A40926, had been isolated and characterized from N. gerenzanensis ATCC 39727. It spans approximately $71 \mathrm{~kb}$ and consists of 37 open reading frames (ORFs) (Sosio et al. 2010).

Until now, fermentation has still been the only approach for the production of A40926 in industrial scale. Therefore, how to improve A40926 titer is one of the essential researches about the rare actinomyces $N$. gerenzanensis. Originally, A40926 yield of the wild-type $N$. gerenzanensis strain was only $5 \mathrm{mg} \mathrm{L}^{-1}$ in an early fermentation study using chemically defined media with high concentrations of phosphate (Gunnarsson et al. 2003). Later studies demonstrated that initially high inorganic phosphate or 
ammonium concentrations inhibited A40926 production (Gunnarsson et al. 2004). Technikova-Dobrova reported that L-GIn, which replaced ammonium or nitrogen as the sole nitrogen in MM-103 medium, could improve the $A 40926$ yield to $123 \mathrm{mg} \mathrm{L}^{-1}$ (Technikova-Dobrova et al. 2004). Chen and colleagues developed a higher-producing strain by mutagenesis with UV irradiation and diethyl sulfate treatment, which presented the highest yield thus far, $1 \mathrm{~g} \mathrm{~L}^{-1}$ of A40926. This group also confirmed that the addition of L-leucine could improve A40926 production. Other studies confirmed that the addition of branchedchain amino acids promotes the production of A40926 and teicoplanin (Chen et al. 2016).

In our recent studies, the positive impacts of the deletion of $d b v 23$ and the overexpression of regulatory $d b v 3$ and $d b v 20$ on A40926 production had been verified, respectively (Yue et al. 2020a). Based on the above founds, we constructed a multiple genetic operating strain laboring the knockout of $d b v 23$ and the co-expression of $d b v 3$ and $d b v 20$. Furthermore, central composition design was carried out to optimize the medium for obtaining the high yield of A40926 by the mutant.

\section{Methods}

\section{Bacterial Strains, Plasmids, and Media}

All bacterial strains and plasmids used in this work are listed in Table 1. N. gerenzanensis and its derivatives were grown on Mannitol-Soy-agar (MS) solid medium at $30^{\circ} \mathrm{C}$ (Marcone et al. 2010). MS medium supplemented with $20 \mathrm{mM} \mathrm{MgCl}_{2}$ was used for intergeneric conjugation between Escherichia coli and mycelia of $N$. gerenzanensis. For seed culture, $50 \mathrm{~mL}$ of VSP medium in 250-mL shake flasks were inoculated with a single colony from solid MS media and cultured at $30^{\circ} \mathrm{C}, 220 \mathrm{rpm}$ for $72 \mathrm{~h}$. For mycelial collection used for intergenic conjugation, the above seed culture was then transferred into 75 $\mathrm{mL}$ of VSP medium in $500-\mathrm{mL}$ shake flask with $4 \%$ inoculum for continuous culture at $30^{\circ} \mathrm{C}$ for $36 \mathrm{~h}$. For A40926 production, a set of media listed in Table 3 were chosen to evaluate their abilities of A40926 production, and which were conducted in the $500-\mathrm{mL}$ shake flasks with four baffles at $30^{\circ} \mathrm{C}$ and $220 \mathrm{rpm}$ for $168 \mathrm{~h}$.

The E. colistrains were cultivated on LB agar medium or in LB liquid medium at $37^{\circ} \mathrm{C}$. Apramycin $(50 \mu \mathrm{g}$ $\left.\mathrm{L}^{-1}\right)$, kanamycin $\left(50 \mu \mathrm{g} \mathrm{L}^{-1}\right)$, chloramphenicol $\left(25 \mu \mathrm{g} \mathrm{L}^{-1}\right)$ and nalidixic acid $\left(25 \mu \mathrm{g} \mathrm{L}^{-1}\right)$, were supplemented when necessary. The $E$. coli strain ET12567/pUZ8002 was used as a donor for intergenic conjugation and delivered recombinant plasmids into $N$. gerenzanensis.

\section{Plasmids Construction}

The sequence of promoter gapdh was synthesized with $\mathrm{Bam} \mathrm{HI} / \mathrm{Nde}$ I sites and further cloned into plJ8660, yielding plJ8660-Pgapdh. The DNA sequence of the promoter gapdh was provided in Supporting information. Isolation of genomic DNA from $N$. gerenzanensis were carried out according to instructions of commercial kits (TIANGEN Biotech Co., Ltd, China). The $d b v 3$ and $d b v 20$ genes were amplified from the genome DNA of $N$. gerenzanensis using the corresponding primers listed in Table 2, respectively. These fragments were cloned into the Eco RV site of pUC57 (Vazyme Biotech Co., Ltd, China), 
respectively. These plasmids carrying different $d b v$ gene were digested with $\mathrm{Ndel}$ and $\mathrm{Not} \mathrm{I}$, and the obtained fragment was cloned into respective sites of plJ8660-Pgapdh to produce plJ8660-Pgapdh-dbv3 and pIJ8660-Pgapdh-dbv20, respectively. To co-overexpress $d b v 3$ and $d b v 20$, the $d b v 3$ fragments with promoter gapdh were amplified from plJ8660 Pgapdh-dbv3 and ligated into plJ8660Pgapdh-dbv20, generating plJ8660Pgapdh-dbv3Pgapdh-dbv20. The expression of $d b v 3$ and $d b v 20$ was driven by the promoter grpdh separately.

\section{Genotype Confirmation of The Exconjugants by PCR}

The exconjugants on the MS medium were transferred into the VSP medium containing $50 \mu \mathrm{g} \mathrm{mL}^{-1}$ apramycin and cultured at $30^{\circ} \mathrm{C}$ and $200 \mathrm{rpm}$ for $48 \mathrm{~h}$. The mycelia were collected and treated for extracting genome DNA by commercial kit. Primers listed in Table 2 were used for confirmative PCR of gapdh-dbv3 and gapdh-dbv20 fusion fragments.

\section{Optimization of A40926 Production Utilizing Central Composite Design (CCD)}

Here, the optimization process of A40926 production was firstly carried out to identify the preferred media for A40926 production based on the literature (Table 3). A novel medium was designed based on the above optimization results. Subsequently, response surface methodology (RSM) was carried out by the central compost design (CCD) to optimize the redesigned medium, which is a complicated statistical method for determining the optimum experimental conditions that require the minimum number of tests. A software Design Expert 11 (Stat-Ease, Inc., USA, Windows operating system) was applied to perform the experimental design matrix and its statistical experimental design analysis. All assays were performed in triplicate.

Three-dimensional curves of the response surfaces were obtained by using Design Expert 11 to visualize individual effects and interaction between significant parameters. The model was evaluated using Fisher 's statistical test for analysis of variance (ANOVA).

\section{Shake Flask Fermentation}

For the shake flask cultivation, the inoculum was prepared by inoculating the mycelia of $N$. gerenzanensis in $50 \mathrm{~mL}$ VSP medium in a $500-\mathrm{ml}$ shake flask. The preculture was incubated at $30^{\circ} \mathrm{C}$ and $200 \mathrm{rpm}$, sustaining for $48 \mathrm{~h}$. Based on the literature reports and novel design, nine different production media (Table 3) were selected for the shake flask tests to evaluate their effects on the A40926 production. All experiments were performed in $500-\mathrm{mL}$ shake flasks, with $75 \mathrm{~mL}$ of medium and a $10 \%(\mathrm{v} / \mathrm{v})$ inoculum prepared as described above. The initial pH was set to 7.2 by the addition of $10 \%$ ammonium hydroxide or $1 \mathrm{M} \mathrm{HCl}$. Cultivation was performed at $30^{\circ} \mathrm{C}$ and $220 \mathrm{rpm}$, for $144 \mathrm{~h}$. At the end of the experiments, the cultivation broth was collected and used to detect the A40926 yield using high-performance liquid chromatography (HPLC). Three replicated tests were conducted for each medium.

\section{Analytical Methods}


The A40926 analysis was similar to that described by Gunnarsson with modifications (Gunnarsson et al. 2003). Briefly, the fermentation broth sample was adjusted to $\mathrm{pH} 11.3$ by adding $\mathrm{NaOH}$ solution, and then sonicated at $50^{\circ} \mathrm{C}$ for $1 \mathrm{~h}$. Subsequently, the sample was centrifuged at 5,000 rpm for $5 \mathrm{~min}$. The supernatant was filtered through a $0.45 \mu \mathrm{m}$ Millipore filter for analysis. A40926 was analyzed by HPLC equipped with a SHIMAZU Shim-pack GIST $\mathrm{C}_{18}$ column $(5 \mu \mathrm{m}, 250 \times 4.60 \mathrm{~mm})$ and a UV detector $(220$ $\mathrm{nm}$ ) (Technikova-Dobrova et al. 2004). The column temperature was $25^{\circ} \mathrm{C}$, the injection volume was 10 $\mu \mathrm{L}$, and the flow rate was $1.0 \mathrm{~mL} \mathrm{~min}^{-1}$. A gradient with two eluents (eluent $\mathrm{A}: 10 \%$ acetonitrile, $90 \% 12.5$ $\mathrm{mM} \mathrm{NaH}{ }_{2} \mathrm{PO}_{4}, \mathrm{pH} 7.8$; eluent B: $50 \%$ acetonitrile, $50 \% 12.5 \mathrm{mM} \mathrm{NaH}_{2} \mathrm{PO}_{4}, \mathrm{pH} 7.8$ ) was applied as follows: (\% eluent B): 0 min, 20\%, 5 min 50\%, 32 min 65\%, 35 min $20 \%$.

\section{Statistical Analysis}

The statistical analyses One-way and Two-way ANOVA were performed using GraphPad Prism version 7.

\section{Results}

Construction of The Engineered Strain Previous studies had verified that the overexpression of positive regulatory gene dbv3 or the deletion of dbv23, encoding an acetyltransferase, could enhance the production of A40926 (Lo Grasso et al. 2015; Sosio et al. 2010; Yue et al. 2020a). In addition, we found that the overexpression of dbv20 gene encoding a mannosyltransferase also improved the A40926 production (Dong et al. 2020). In this study, a strategy of multiple genetic operations referring to coexpressing dbv3 and dbv20 in a dbv23-deleted mutant was adopted to improve the strain. The two dbv genes were separately and simultaneously expressed under the control of each promoter gapdh (Fig. 1A). The recombinant plasmid was transferred to the mutant $\Delta 23$ by conjugation, which was expected to obtain the final mutant verified by PCR. As a result, the fragments of Pgapdh-dbv3 and Pgapdh-dbv20 were successfully obtained and about $0.7 \mathrm{~kb}$ size (Fig. 1B). Furthermore, we compared the A40926 yield of mutant with that of the other control strains including the original strain $(\Delta 23)$, the wild-type strain, the dbv3-overexpressed stain (op3) and the dbv20-overexpressed strain (op20). As expected, the coexpression of dbv3 and dbv20 further improved the A40926 yield, which increased from 159 to $262 \mathrm{mg} \mathrm{L-}$ 1 compared with the wild-type strain (Fig. 1C). Media Screening Experiments Previous studies had reported some suitable media for A40926 production (Table 3). In this work, we applied these media to evaluate their capabilities for A40926 production, and further redesigned medium and optimized the components. The fermentation results demonstrated that the more kinds of natural components, such as maltodextrin, soybean meal, peptone, and corn starch, were contained in the medium, and the higher the yield of A40926 was (Fig. 2). Based on the results, a novel combination medium was designed and named M9, which was composed of carbon resource of glucose and maltodextrin, nitrogen resource of peptone and soybean meal, the amino acid of L-valine, and other inorganic salts. In contrast to media from literature, the engineered strain gave the highest yield of A40926 in M9 medium as expected. It was supposed that the proper ratio of carbon and nitrogen resource, the relative lower viscosity of the medium, and more various inorganic salts were beneficial to improve the A40926 production.

Optimization of Medium Components for A40926 Production by CCD To further optimize the components 
of M9 medium, central composition design was applied. The optimization process focused on investigating the impact of five independent variables: glucose $(A)$ and maltodextrin (B) as carbon sources, soybean meal (C) and peptone (D) as nitrogen sources, L-valine as a precursor (E), on the yield of A40926, using response surface methodology based on central composite design (Table 4). A statistically designed study was performed to evaluate the individual and the interactive effect of five medium ingredients on the A40926 yield. The values of response from the 32 experiments are presented in Fig. 3. The first set of optimal statistical conditions, maximizing A40926 yield by N. gerenzanensis were obtained with 28-32 standard tests (Supplementary Table 1) which corresponded to the medium composition including glucose 10 (g L-1), maltodextrin 35 (g L-1), soybean meal 30\% (g L-1), peptone 20 ( $\mathrm{g} \mathrm{L}-1)$, and L-valine 3.5 (g L-1). Here, RSM is a five factorial design where 3D contour plots of surface curves (Fig. 4 and Supplementary Fig. 1) can be generated by linear effects, quadratic effects and twoway interactions between the factors. From these profiles, a semi-empiric model (Eq.1) can be derived that best fits the experimental data. The parameters and results of the CCD experiments are presented in Table 4, Fig. 3 and 4, and Supplementary Table 1 and Fig 1. The statistical significance of the quadratic model was tested by F-and $\mathrm{p}$-values (Table 5). The results from ANOVA indicated that the quadratic regression used to produce a second-order model was significant, as revealed from the $\mathrm{p}$ - and F-values: the calculated Model F-value of 37.53 and the $p$-value of $<0.0001$ indicate that the model is significant. The Lack of Fit F-value of 0.45 implies that the Lack of Fit is not significant relative to the pure error. There is $81.52 \%$ chance that a Lack of Fit F-value this large could occur due to noise. The second-order polynomial equation of the model fitted for A40926 production before eliminating the non-significant terms is: A40926 production yield $(\mathrm{mg} / \mathrm{l})=64.4097+0.929924{ }^{\star} \mathrm{A}+3.31465^{\star} \mathrm{B}+9.69432^{\star} \mathrm{C}+0.885795^{\star} \mathrm{D}+$ $8.7298 * \mathrm{E}-0.0275^{\star} \mathrm{AB}+0.03375^{\star} \mathrm{AC}-0.02875^{\star} \mathrm{AD}+0.175^{\star} \mathrm{A} E-0.00208333^{\star} \mathrm{BC}-0.00958333^{*} \mathrm{BD}+0.0472222{ }^{*}$ $B E-0.006875{ }^{*} \mathrm{CD}+0.0541667{ }^{*} \mathrm{CE}+0.179167 * \mathrm{DE}-0.0404545 * \mathrm{~A} 2-0.0389394 * \mathrm{~B} 2-0.145114{ }^{*} \mathrm{C} 2-$

$0.0126136 * D 22.22727 * E 2$ (Eq. 1) (Degree of freedom=20; F-value $=37.53 ; p$-value $<0.0001 ; R 2=0.9856$ ) In this study, the model terms with the values of $p$-value Prob > F (Table 5) lower than 0.05 was considered as the significant terms. On the contrary, if the $p$-value Prob $>F$ is higher than 0.1 , the model terms are non-significant. In this case, the model terms B (maltodextrin), C (soybean meal), E (L-valine), $\mathrm{DE}, \mathrm{B} 2, \mathrm{C} 2$, and $\mathrm{E} 2$ were considered significant. The $\mathrm{R} 2$ value provides a measure of how much variability in the observed response values can be explained by the experimental factors and their interactions. The closer the R2 value to 1.00 , the stronger the model is, and the better it predicted the observed response. It was suggested that the $\mathrm{R} 2$ value should be at least 0.80 , for a good model fitness(Venkatachalam et al. 2020). Here, the calculated R2 value of 0.9543 (Supplementary Table 2), indicated that $4.57 \%$ of the total variation could not be explained by the empirical model; this expresses a good enough quadratic fit to navigate the design space. Thus, the response surface model developed in this study for predicting the A40926 production may be considered satisfactory (Eq. 2). The signal to noise ratio was measured by Adeq Precision value of 33.0287, which indicated that this model could be used to navigate the design space. From the above, the second-order polynomial equation of the model fitted for A40926 production, after eliminating the non-significant terms (Supplementary Table 2), is A40926 production yield (mg L$1)=323.91+3.37 * \mathrm{~B}+13.04{ }^{*} \mathrm{C}+2.63{ }^{*} \mathrm{E}+2.69 * \mathrm{DE}-8.59{ }^{*} \mathrm{~B} 2-14.34{ }^{*} \mathrm{C} 2-4.84{ }^{*} \mathrm{E} 2$ (Eq. 2) (Degree of freedom=7; Fvalue $=71.54 ; p$-value $<0.0001 ; R 2=0.9543$ ) Whereby the F-value increased, meaning that the mean 
squares of the model are larger than the square residual average. Thus, with a higher the F-value, the more significant $p$-value for ANOVA and the more significant the model is. Effect of Significant Components on A40926 Production 3D response surface graphs (Fig. 4 and Supplementary Fig. 1) were plotted to illustrate the interaction of the different paired factors and to determine the optimum of each paired factor for maximum response. Each graph represents the combinations of two test factors in relation to A40926 production yield. The data in Fig. 4 indicate that the increase in significant carbon source (maltodextrin) and amino acid/nitrogen sources (soybean meal, peptone, and L-valine) resulted in increased A40926 production. From the combined effect of maltodextrin and soybean meal concentration (Fig. 4A), the highest production was obtained by the appropriate soybean meal concentration and the proper maltodextrin concentration. Similar results were obtained with the combined effect of L-valine and maltodextrin (Fig. 4B). The effects of L-valine and peptone concentrations, and of L-valine and soybean meal, on A40926 production yield are illustrated in Fig. 4C and 4D. Yield increased as the concentrations of soybean meal and L-valine increased and decreased, respectively. The main medium combination of $L$-valine and peptone ( $D E$, Table 5 ) showed the highest $p$ value for Prob > F (0.0264) and therefore represented a more significant model term combination. Lvaline is a well-known precursor for A40926 production and meanwhile is a source of nitrogen(Alduina et al. 2018; Beltrametti et al. 2004; Yue et al. 2020b). It is possible that higher concentrations of these nutrients could have led to a substrate growth inhibition and/or affected A40926 production. The optimal concentrations of the four factors excluding factor glucose that maximized A40926 production yield were predicted using the optimization function of the statistical experimental designs Design Expert 11. Glucose 10 (g L-1), maltodextrin 37.9 (g L-1), soybean meal 34.5 (g L-1), peptone 30.0 (g L-1), and Lvaline 4.3 ( $\mathrm{g} \mathrm{L}-1)$ were chosen as the optimal concentrations, resulting in the highest A40926 yield of $328.6 \mathrm{mg} \mathrm{L}-1$. The predicted medium composition roughly coincided with experiment trials from 27 to 32 (Supplementary Table 1). No statistical differences were observed between the predicted maximum production yield and the experimental results $(p>0.05)$. The optimized results were also confirmed $(p>$ 0.05 ) by conducting a further fermentation experiment in triplicate at the above-optimized values, resulting in production yield of $332 \pm 13 \mathrm{mg} \mathrm{L}-1$. A Parity plot illustrating the distribution of experimental (actual) and predicted (model) values is shown in Fig. 5. Data points are scattered along the diagonal line, also suggesting that the model is adequate to explain A40926 production within the experimental range studied. The process profiles of A40926 production shown in Fig. 6 obtained by the cultivation of the engineered strain Icu1 in the non-optimized and optimized media, respectively. Here, the strain Icu1 was denominated by the abbreviation of Liaocheng University number one, and which has the genetic characteristics of the dbv23 gene deletion and the dbv3-dbv20 gene co-expression. During the first $48 \mathrm{~h}$ of culture, there was no difference in the two media for A40926 production. Subsequently, the productivity of A40926 in the optimized medium was always higher than that in the non-optimized medium. In particular, the biosynthesis of A40926 stagnated and even decreased in the last $24 \mathrm{~h}$ of fermentation. The yield of A40926 in the optimized medium reached $332 \mathrm{mg} \mathrm{L-1}$ at the end of fermentation, which was significantly higher than that of $257 \mathrm{mg} \mathrm{L}-1$ in the non-optimized medium.

\section{Discussion}


In this study, we combined the genetic manipulation of $d b v$ genes and the traditional media optimization to enhance the production of A40926. The strategy brought a significant increase of A40926 yield by 65.2 percent, which exceeded our expectations. The previous researches referring to the $d b v$ cluster gave us a comprehensive understanding of the biosynthesis of A40926. For instance, the pathway-specific regulatory gene $d b v 3$ and $d b v 4$ were verified to play positive roles in the A40926 production (Alduina et al. 2007; Lo Grasso et al. 2015). The post-modified genes in $d b v$ cluster exerted significant roles in the biosynthesis of A40926, which included seven genes such as $d b v 8$ encoding an acyltransferase (Kruger et al. 2005), $d b v 21$ encoding a deacetylase (Ho et al. 2006), $d b v 23$ encoding an acetyltransferase (Sosio et al. 2010), and $d b v 29$ encoding a hexose oxidase (Liu et al. 2011). Typically, the absence of $d b v 23$ distinctively promoting the production of A40926 had been confirmed by Sosio's and our previous studies (Sosio et al. 2010; Yue et al. 2020a). Recently, the overexpression of the $d b v 20$ gene, encoding a mannosyltransferase, was verified to improve the A40926 production (Dong et al. 2020). Here, we constructed an engineered strain with the deletion of $d b v 23$ and the co-expression of $d b v 3$ and $d b v 20$ to improve the A40926 yield actually.

To further improve the A40926 production, the preferred nutrients, including carbon and nitrogen sources for A40926 production, were determined based on the literature and the preliminary fermentation assays. As shown in the results (Fig. 3), the delayed natural carbon and nitrogen sources such as maltodextrin and soybean meal were beneficial to producing A40926. Nevertheless, it should be noted that the higher concentration of these delayed carbon and nitrogen sources, such as corn starch and soybean meal, resulted in a decrease of A40926 yield, which might be caused by the limitation of the dissolved oxygen transfer. Therefore, we designed a novel medium M9 based on the comprehensive consideration of viscosity related to oxygen transfer and the mixture of the delayed and quick-acting carbon and nitrogen sources. The M9 medium led to the highest yield of A40926 among the screened media.

Furthermore, response surface methodology with central composite design was carried out to obtain a mathematical model to identify the optimum concentrations of the significant components for the improvement of A40926 production. The most optimal concentrations of significant medium components were glucose $10 \mathrm{~g} \mathrm{~L}^{-1}$, maltodextrin $37.9 \mathrm{~g} \mathrm{~L}^{-1}$, soybean meal $34.5 \mathrm{~g} \mathrm{~L}^{-1}$, peptone $30.0 \mathrm{~g} \mathrm{~L}^{-}$ 1 , and L-valine $4.3 \mathrm{~g} \mathrm{~L}^{-1}$. The maximum yield $332 \mathrm{mg} \mathrm{L}^{-1}$ of $\mathrm{A} 40926$ was obtained. Therefore, the response surface statistical methods should be effective for optimizing the medium nutrients for the production of secondary metabolites from microorganisms.

\section{Declarations}

\section{Conflict of interest statement}

The authors declare that they have no conflict of interest.

\section{Ethical approval}


This article does not contain any studies with human participants or animals performed by any of the authors.

\section{Acknowledgment}

This work was supported by the Natural Science Foundation of Shandong Province (Grant no. ZR2015CL001).

\section{References}

Alduina R, Lo Piccolo L, D'Alia D, Ferraro C, Gunnarsson N, Donadio S, Puglia AM (2007) Phosphatecontrolled regulator for the biosynthesis of the dalbavancin precursor A40926 J Bacteriol 189:8120-8129 doi:10.1128/JB.01247-07

Alduina R, Sosio M, Donadio S (2018) Complex Regulatory Networks Governing Production of the Glycopeptide A40926 Antibiotics (Basel) 7 doi:10.3390/antibiotics7020030

Beltrametti F, Jovetic S, Feroggio M, Gastaldo L, Selva E, Marinelli F (2004) Valine influences production and complex composition of glycopeptide antibiotic A40926 in fermentations of Nonomuraea sp. ATCC 39727 J Antibiot (Tokyo) 57:37-44 doi:10.7164/antibiotics.57.37

Chen CF ZH, Zhang CQ, Hu HF (2015) Breeding the high-producer of A40926 and improving its fermentation technology Chinese Journal of Antibiotics 40:28-32 doi:https://doi.org/10.3969/j.issn.10018689.2015.01.005

Chen M, Xu T, Zhang G, Zhao J, Gao Z, Zhang C (2016) High-yield production of lipoglycopeptide antibiotic A40926 using a mutant strain Nonomuraea sp. DP-13 in optimized medium Prep Biochem Biotechnol 46:171-175 doi:10.1080/10826068.2015.1015561

Dong H, Yue X, Yan B, Gao W, Wang S, Li Y (2020) Improved A40926 production from Nonomuraea gerenzanensis using the promoter engineering and the co-expression of crucial genes $\mathrm{J}$ Biotechnol 324:28-33 doi:10.1016/j.jbiotec.2020.09.017

Goldstein BP et al. (1987) A40926, a new glycopeptide antibiotic with anti-Neisseria activity Antimicrob Agents Chemother 31:1961-1966 doi:10.1128/aac.31.12.1961

Gunnarsson N, Bruheim P, Nielsen J (2003) Production of the glycopeptide antibiotic A40926 by Nonomuraea sp. ATCC 39727: influence of medium composition in batch fermentation J Ind Microbiol Biotechnol 30:150-156 doi:10.1007/s10295-003-0024-6

Gunnarsson N, Bruheim P, Nielsen J (2004) Glucose metabolism in the antibiotic producing actinomycete Nonomuraea sp. ATCC 39727 Biotechnol Bioeng 88:652-663 doi:10.1002/bit.20279 
Gust B, Challis GL, Fowler K, Kieser T, Chater KF (2003) PCR-targeted Streptomyces gene replacement identifies a protein domain needed for biosynthesis of the sesquiterpene soil odor geosmin Proc Natl Acad Sci U S A 100:1541-1546 doi:10.1073/pnas.0337542100

Ho JY, Huang YT, Wu CJ, Li YS, Tsai MD, Li TL (2006) Glycopeptide biosynthesis: Dbv21/Orf2 from $\mathrm{dbv/tcp}$ gene clusters are N-Ac-GIm teicoplanin pseudoaglycone deacetylases and Orf15 from cep gene cluster is a Glc-1-P thymidyltransferase J Am Chem Soc 128:13694-13695 doi:10.1021/ja0644834

Huang LL SX, Chen SX (2012) Optimization of fermentation medium and mutation breeding a glycopeptide antibiotic A40926 B producing strain Chinese journal of pharmaceuticals 43:256-259 doi:https://doi.org/10.3969/j.issn.1001-8255.2012.04.006

Jovetic S, Feroggio M, Marinelli F, Lancini G (2008) Factors influencing cell fatty acid composition and A40926 antibiotic complex production in Nonomuraea sp. ATCC $39727 \mathrm{~J}$ Ind Microbiol Biotechnol 35:1131-1138 doi:10.1007/s10295-008-0392-z

Kruger RG, Lu W, Oberthur M, Tao J, Kahne D, Walsh CT (2005) Tailoring of glycopeptide scaffolds by the acyltransferases from the teicoplanin and A-40,926 biosynthetic operons Chem Biol 12:131-140 doi:10.1016/j.chembiol.2004.12.005

Liu YC et al. (2011) Interception of teicoplanin oxidation intermediates yields new antimicrobial scaffolds Nat Chem Biol 7:304-309 doi:10.1038/nchembio.556

Liu ZY LJ, Zhu BF, et al (2018) High-throughput screening for A40926 high producing strain Chinese Journal of Pharmaceuticals 49:316-321 doi:https://doi.org/10.16522/j.cnki.cjph.2018.03.008

Lo Grasso L, Maffioli S, Sosio M, Bibb M, Puglia AM, Alduina R (2015) Two Master Switch Regulators Trigger A40926 Biosynthesis in Nonomuraea sp. Strain ATCC 39727 J Bacteriol 197:2536-2544 doi:10.1128/JB.00262-15

Marcone GL, Binda E, Carrano L, Bibb M, Marinelli F (2014) Relationship between glycopeptide production and resistance in the actinomycete Nonomuraea sp. ATCC 39727 Antimicrob Agents Chemother 58:51915201 doi:10.1128/AAC.02626-14

Marcone GL, Carrano L, Marinelli F, Beltrametti F (2010) Protoplast preparation and reversion to the normal filamentous growth in antibiotic-producing uncommon actinomycetes J Antibiot (Tokyo) 63:83-88 doi:10.1038/ja.2009.127

Marschall E, Cryle MJ, Tailhades J (2019) Biological, chemical, and biochemical strategies for modifying glycopeptide antibiotics J Biol Chem 294:18769-18783 doi:10.1074/jbc.REV119.006349

Sosio M, Canavesi A, Stinchi S, Donadio S (2010) Improved production of A40926 by Nonomuraea sp. through deletion of a pathway-specific acetyltransferase Appl Microbiol Biotechnol 87:1633-1638 doi:10.1007/s00253-010-2579-2 
Sun J, Kelemen GH, Fernandez-Abalos JM, Bibb MJ (1999) Green fluorescent protein as a reporter for spatial and temporal gene expression in Streptomyces coelicolor A3(2) Microbiology (Reading) 145 ( Pt 9):2221-2227 doi:10.1099/00221287-145-9-2221

Technikova-Dobrova Z et al. (2004) Design of mineral medium for growth of Actinomadura sp. ATCC 39727, producer of the glycopeptide A40926: effects of calcium ions and nitrogen sources Appl Microbiol Biotechnol 65:671-677 doi:10.1007/s00253-004-1626-2

Venkatachalam M, Shum-Cheong-Sing A, Dufosse L, Fouillaud M (2020) Statistical Optimization of the Physico-Chemical Parameters for Pigment Production in Submerged Fermentation of Talaromyces albobiverticillius 30548 Microorganisms 8 doi:10.3390/microorganisms8050711

Yan L HC, Zhu CY, et al (2013) Breeding high-producer of glycopeptide antibiotic A40926 Chinese Journal of Pharmaceuticals 44:143-145

Yim G, Thaker MN, Koteva K, Wright G (2014) Glycopeptide antibiotic biosynthesis J Antibiot (Tokyo) 67:31-41 doi:10.1038/ja.2013.117

Yue X, Xia T, Wang S, Dong H, Li Y (2020a) Highly efficient genome editing in N. gerenzanensis using an inducible CRISPR/Cas9-RecA system Biotechnol Lett 42:1699-1706 doi:10.1007/s10529-020-02893-2

Yue X, Yan B, Wang S, Gao W, Zhang R, Dong H (2020b) Preparation of pH-Responsive Alginate-Chitosan Microspheres for L-Valine Loading and Their Effects on the A40926 Production Curr Microbiol 77:10161023 doi:10.1007/s00284-020-01894-8

\section{Tables}

\section{Table 1 Strains and plasmids used in this work}




\begin{tabular}{|c|c|c|}
\hline $\begin{array}{l}\text { Strains or } \\
\text { plasmids }\end{array}$ & Characteristics $^{a}$ & $\begin{array}{l}\text { Sources } \\
\text { or } \\
\text { reference }\end{array}$ \\
\hline \multicolumn{3}{|l|}{ Escherichia coli } \\
\hline DH5a & Routine subcloning host & Invitrogen \\
\hline ET12567/pUZ8002 & $\begin{array}{l}\text { Derived from the methylation-defective strain ET12567 carrying } \\
\text { plasmid and donor strain for E. coli-Actinomyces conjugation }\end{array}$ & $\begin{array}{l}\text { (Gust et } \\
\text { al. 2003) }\end{array}$ \\
\hline \multicolumn{3}{|l|}{ Actinomyces } \\
\hline $\begin{array}{l}\text { N. gerenzanensis } \\
\text { ATCC } 39727\end{array}$ & Wild-type, glycopeptide A40926 producer & $\begin{array}{l}\text { (Goldstein } \\
\text { et al. } \\
1987 \text { ) }\end{array}$ \\
\hline$\Delta 23$ & $N$. gerenzanensis mutant with the knockout of $d b v 23$ gene & $\begin{array}{l}\text { (Yue et al. } \\
\text { 2020a) }\end{array}$ \\
\hline Icu1 & $\Delta 23$ strain laboring plJ8660-gapdhp-dbv3-gapdhp-dbv20 & $\begin{array}{l}\text { This } \\
\text { study }\end{array}$ \\
\hline \multicolumn{3}{|l|}{ Plasmids } \\
\hline plJ8660 & A pSET152 derivative. Apr ${ }^{r}$ & $\begin{array}{l}\text { (Sun et al. } \\
\text { 1999) }\end{array}$ \\
\hline plJ8660-Pgapdh & plJ8660 plasmid with promoter gapdh & $\begin{array}{l}\text { This } \\
\text { study }\end{array}$ \\
\hline $\begin{array}{l}\text { plJ8660Pgapdh- } \\
\text { dbv3Pgapdh-bv20 }\end{array}$ & plJ8660 plasmid with two promoter gapdh, $d b v 3$ and $d b v 20$ & $\begin{array}{l}\text { This } \\
\text { study }\end{array}$ \\
\hline
\end{tabular}

a: Apr', apramycin resistance

Table 2 Oligonucleotides and Primers used in this work 


\begin{tabular}{lll} 
Primers & Sequence $\left(5^{\prime}-3^{\prime}\right)$ & Description \\
\hline p1/p2 & $\begin{array}{l}\text { tgaaaggggatacgccatatggtgctgttcgggcgagatcgtg } \\
\text { acgggctgcagccgggcggccgcctacagccgcactgcctcacg }\end{array}$ & Amplification for $d b v 3$ \\
\hline p3/p4 & $\begin{array}{l}\text { tgaaaggggatacgccatatgatgtcgcacatcaccatgactc } \\
\text { acgggctgcagccgggcggtacctcagcccccgggtgtccg }\end{array}$ & Amplification for $d b v 20$ \\
\hline p5/p6 & gctgctccttcggtcggacgtgcgtctacg & Verification of Icu1 strain \\
& cacggcccagatcgcccacacctcctccgg & \\
\hline p7/p8 & $\begin{array}{l}\text { gctgctccttcggtcggacgtgcgtctacg } \\
\text { tccggtacatcaccagcaccgagatcacgc }\end{array}$ & Verification of Icu1 strain \\
\end{tabular}

Table 3 Media used for the cultivation of the engineered $N$. gerenzanensis Icu1 in this study 


\begin{tabular}{|c|c|c|c|c|c|c|c|c|c|}
\hline Component $\left(\mathrm{g} \mathrm{L}^{-1}\right)$ & M1 & M2 & M3 & M4 & M5 & M6 & M7 & M8 & M9 \\
\hline Glucose & 10 & 20 & 20 & 50 & 20 & 5 & 30 & 5 & 10 \\
\hline Maltodextrin & & & 50 & & 15 & 30 & & & 30 \\
\hline Peptone & & & 10 & & & & & & 15 \\
\hline Yeast extract & & & 10 & & & 5 & 8 & & \\
\hline Soybean meal & & & 20 & 10 & & 10 & 30 & 30 & 20 \\
\hline Corn starch & & & & & 40 & 30 & & 40 & \\
\hline Soluble starch & & & & & & 10 & & & \\
\hline Tryptone & & & & & 15 & & & & \\
\hline Cottonseed meal & & & & 10 & & 5 & & & \\
\hline Soybean protein & & & & 5 & 40 & 5 & & & \\
\hline Meat peptone & & & & & & 10 & & & \\
\hline Soybean oil & & & & 10 & 10 & & & & \\
\hline Fish powder/peptone & & & & & & & & 15 & \\
\hline Malt extract & & & & & & & 15 & & \\
\hline Casein & & & & & & & & 2 & \\
\hline L-Leu & & 0.5 & 3 & 1 & & & & & \\
\hline L-Gln & 2 & & & 1.5 & & & & & \\
\hline L-Val & & 0.5 & & & & 1 & 1 & 1 & 5 \\
\hline L-Tyr & & & & 0.5 & & & & & \\
\hline L-lle & & 0.5 & & & & & & & \\
\hline $\mathrm{K}_{2} \mathrm{HPO}_{4}$ & 0.5 & & & & & & & & \\
\hline $\mathrm{KH}_{2} \mathrm{PO}_{4}$ & & 0.65 & & 1.5 & & & & & 0.5 \\
\hline $\mathrm{MgSO}_{4} \cdot 7 \mathrm{H}_{2} \mathrm{O}$ & 0.2 & 0.45 & & 0.2 & & & & & 0.4 \\
\hline $\mathrm{FeSO}_{4} \cdot 7 \mathrm{H}_{2} \mathrm{O}$ & 0.01 & & & & & & & & 0.2 \\
\hline$\left(\mathrm{NH}_{4}\right)_{2} \mathrm{SO}_{4}$ & & 3.65 & & 2 & & & & & \\
\hline $\mathrm{CaCO}_{3}$ & & & 5 & & & & 4 & 4 & 3 \\
\hline $\mathrm{NaCl}$ & & & 2 & & & & & & 2 \\
\hline
\end{tabular}


$\mathrm{CuSO}_{4}$

$\begin{array}{llllllllll}\mathrm{pH} & 7.0-7.2 & 7.5 & 7.0 & 7.0 & 6.5 & 7.0 & 7.4 & 7.0 & 7.2 \\ \text { References } & \mathrm{a} & \mathrm{b} & \mathrm{c} & \mathrm{d} & \mathrm{e} & \mathrm{f} & \mathrm{g} & \mathrm{h} & \text { This study }\end{array}$

a, (Technikova-Dobrova et al. 2004); b, (Jovetic et al. 2008); c, (Chen et al. 2016); d, (Yan L 2013); e, (Liu ZY 2018); f, (Huang LL 2012); g, (Marcone et al. 2014); h, (Chen CF 2015).

Table 4 Levels of carbon and nitrogen resources selected for the experimental central composite design

\begin{tabular}{|llllllll|}
\hline Factor & Name & Units & Min & Max & Low & High & Mean \\
\hline A & Glucose & $\mathrm{g} \mathrm{L}^{-1}$ & 0.0 & 20.0 & 5.0 & 15.0 & 10.0 \\
\hline B & Maltodextrin & $\mathrm{g} \mathrm{L}^{-1}$ & 5.0 & 65.0 & 20.0 & 50.0 & 35.0 \\
\hline C & Soybean meal & $\mathrm{g} \mathrm{L}^{-1}$ & 10.0 & 50.0 & 20.0 & 40.0 & 30.0 \\
\hline D & Peptone & $\mathrm{g} \mathrm{L}^{-1}$ & 0.0 & 40.0 & 10.0 & 30.0 & 20.0 \\
E & L-valine & $\mathrm{g} \mathrm{L}^{-1}$ & 0.5 & 6.5 & 2.0 & 5.0 & 3.5 \\
\hline
\end{tabular}

Table 5 Analysis of variance (ANOVA) for the quadratic model based on Response Surface Method ${ }^{\text {a }}$ 


\begin{tabular}{|c|c|c|c|c|c|c|}
\hline Source & $\begin{array}{l}\text { Sum of } \\
\text { Squares }\end{array}$ & Df & $\begin{array}{l}\text { Mean } \\
\text { Square }\end{array}$ & $\begin{array}{l}F- \\
\text { value }\end{array}$ & $\begin{array}{l}p \text {-value (prob. } \\
>F \text { ) }\end{array}$ & \\
\hline Model & 13199.26 & 20 & 659.96 & 37.53 & $<0.0001$ & significant \\
\hline A-Glucose & 26.04 & 1 & 26.04 & 1.48 & 0.2491 & \\
\hline B-Maltodextrin & 273.37 & 1 & 273.37 & 15.54 & 0.0023 & significant \\
\hline C-Soybean meal & 4082.04 & 1 & 4082.04 & 232.11 & $<0.0001$ & significant \\
\hline D-Peptone & 77.04 & 1 & 77.04 & 4.38 & 0.0603 & \\
\hline E-L-valine & 165.38 & 1 & 165.38 & 9.40 & 0.0107 & significant \\
\hline$A B$ & 68.06 & 1 & 68.06 & 3.87 & 0.0749 & \\
\hline$A C$ & 45.56 & 1 & 45.56 & 2.59 & 0.1358 & \\
\hline$A D$ & 33.06 & 1 & 33.06 & 1.88 & 0.1977 & \\
\hline $\mathrm{AE}$ & 27.56 & 1 & 27.56 & 1.57 & 0.2366 & \\
\hline $\mathrm{BC}$ & 1.56 & 1 & 1.56 & 0.0888 & 0.7712 & \\
\hline BD & 33.06 & 1 & 33.06 & 1.88 & 0.1977 & \\
\hline BE & 18.06 & 1 & 18.06 & 1.03 & 0.3326 & \\
\hline CD & 7.56 & 1 & 7.56 & 0.4300 & 0.5255 & \\
\hline CE & 10.56 & 1 & 10.56 & 0.6006 & 0.4547 & \\
\hline DE & 115.56 & 1 & 115.56 & 6.57 & 0.0264 & significant \\
\hline$A^{2}$ & 30.00 & 1 & 30.00 & 1.71 & 0.2182 & \\
\hline$B^{2}$ & 2251.67 & 1 & 2251.67 & 128.03 & $<0.0001$ & significant \\
\hline $\mathrm{C}^{2}$ & 6177.00 & 1 & 6177.00 & 351.23 & $<0.0001$ & significant \\
\hline$D^{2}$ & 46.67 & 1 & 46.67 & 2.65 & 0.1316 & \\
\hline$E^{2}$ & 736.67 & 1 & 736.67 & 41.89 & $<0.0001$ & significant \\
\hline Residual & 193.45 & 11 & 17.59 & & & \\
\hline Lack of Fit & 68.62 & 6 & 11.44 & 0.4581 & 0.8152 & $\begin{array}{l}\text { not } \\
\text { significant }\end{array}$ \\
\hline Pure Error & 124.83 & 5 & 24.97 & & & \\
\hline Corrected Total & 13392.72 & 31 & & & & \\
\hline $\mathrm{R}^{2}$ & & & & & 0.9856 & \\
\hline Adjusted $\mathrm{R}^{2}$ & & & & & 0.9593 & \\
\hline
\end{tabular}


Precision

a, before eliminating the non-significant terms.

\section{Figures}

A

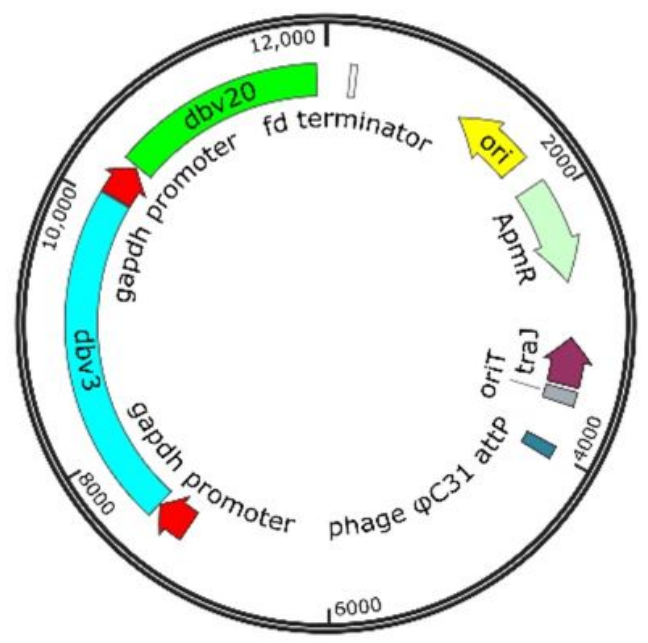

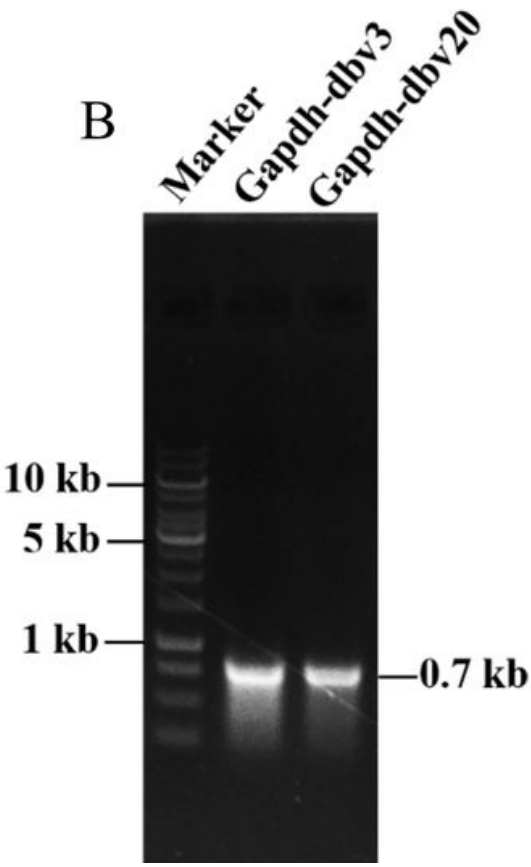

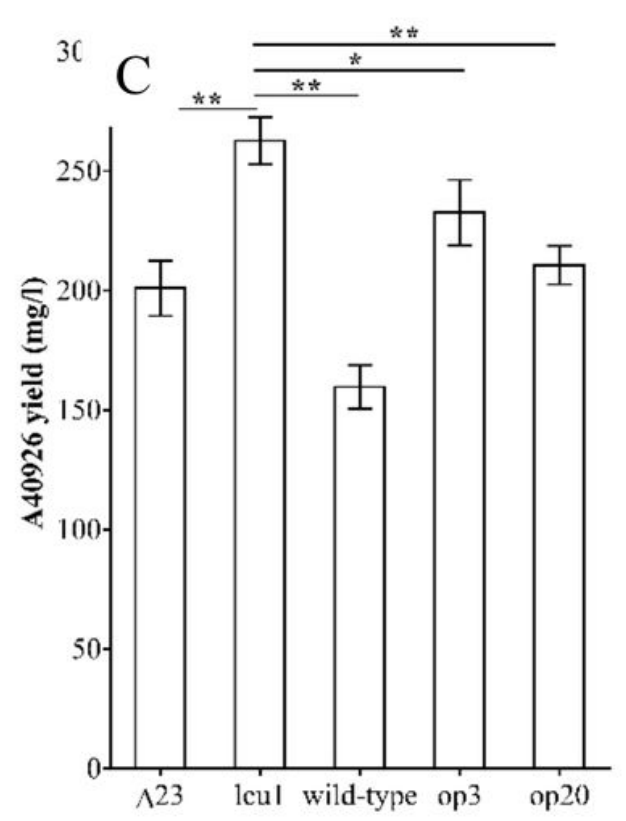

Figure 1

The recombinant plasmid plJ8660-Pgapdh-dbv3-Pgapdh-dbv20 (A), PCR verification (B), and fermentation assay of the different strains (C). 


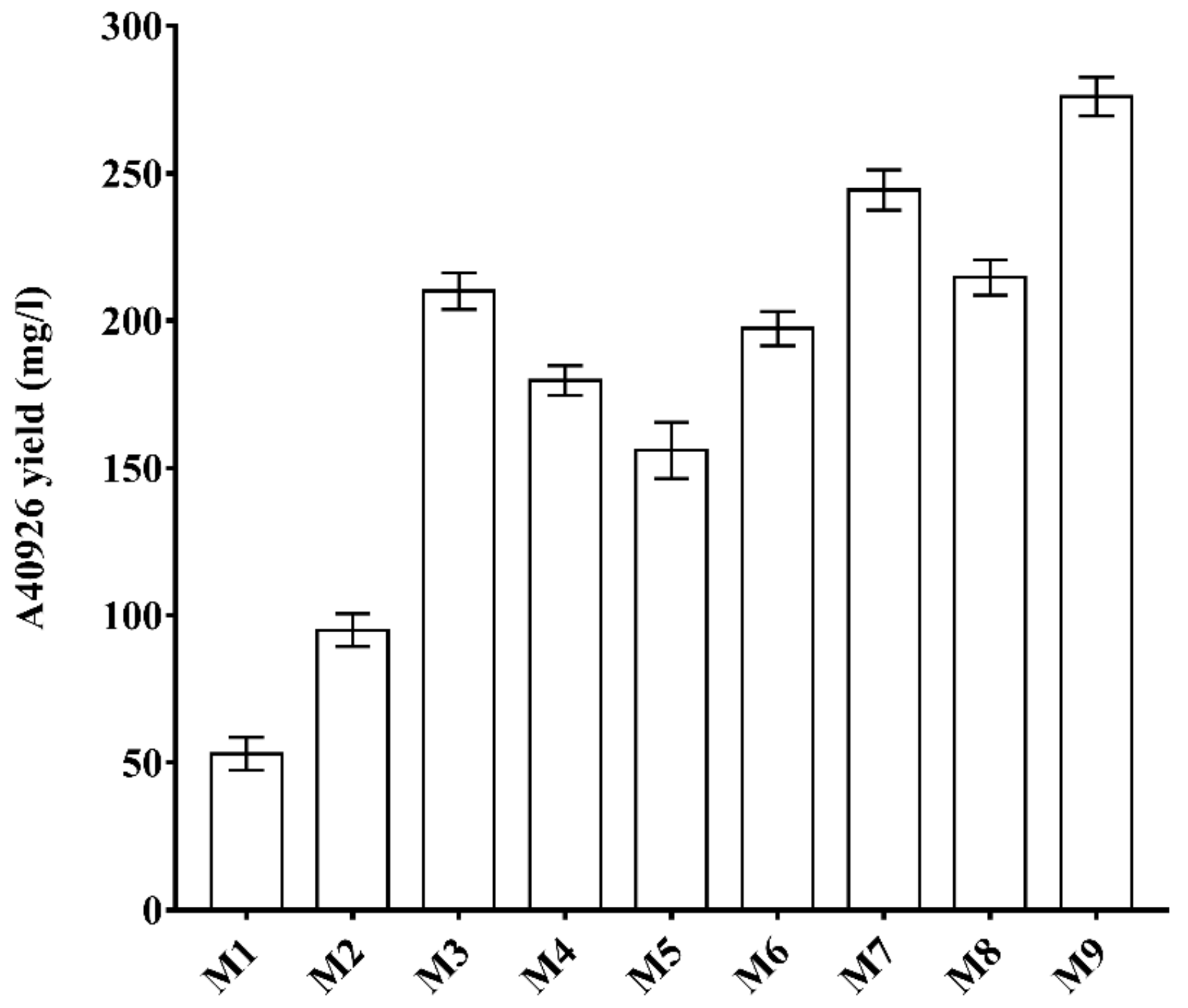

Figure 2

Comparison of A40926 yield produced by engineered N. gerenzanensis strain in different media. 


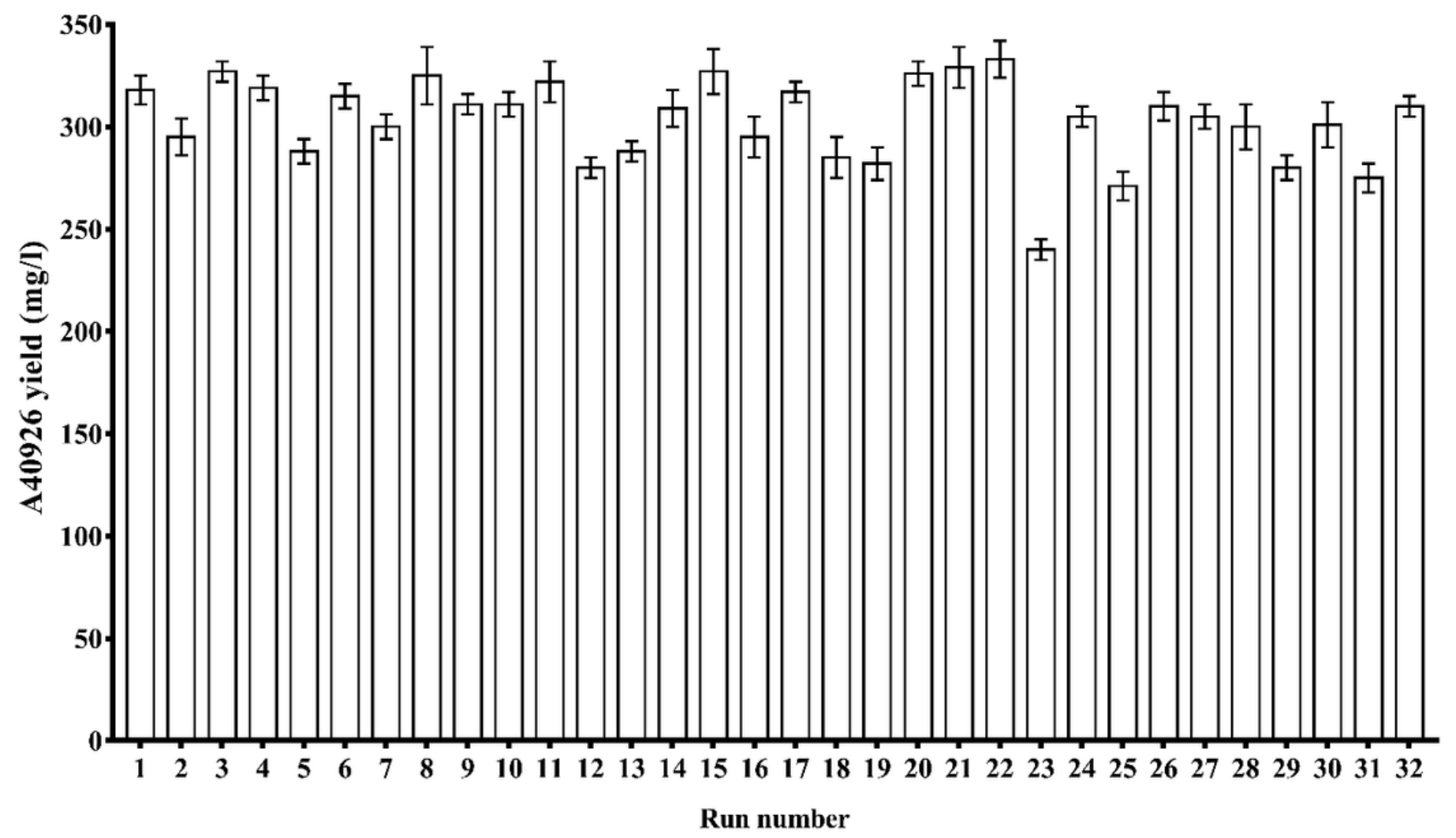

Figure 3

The response values of A40926 from 32 tests. 

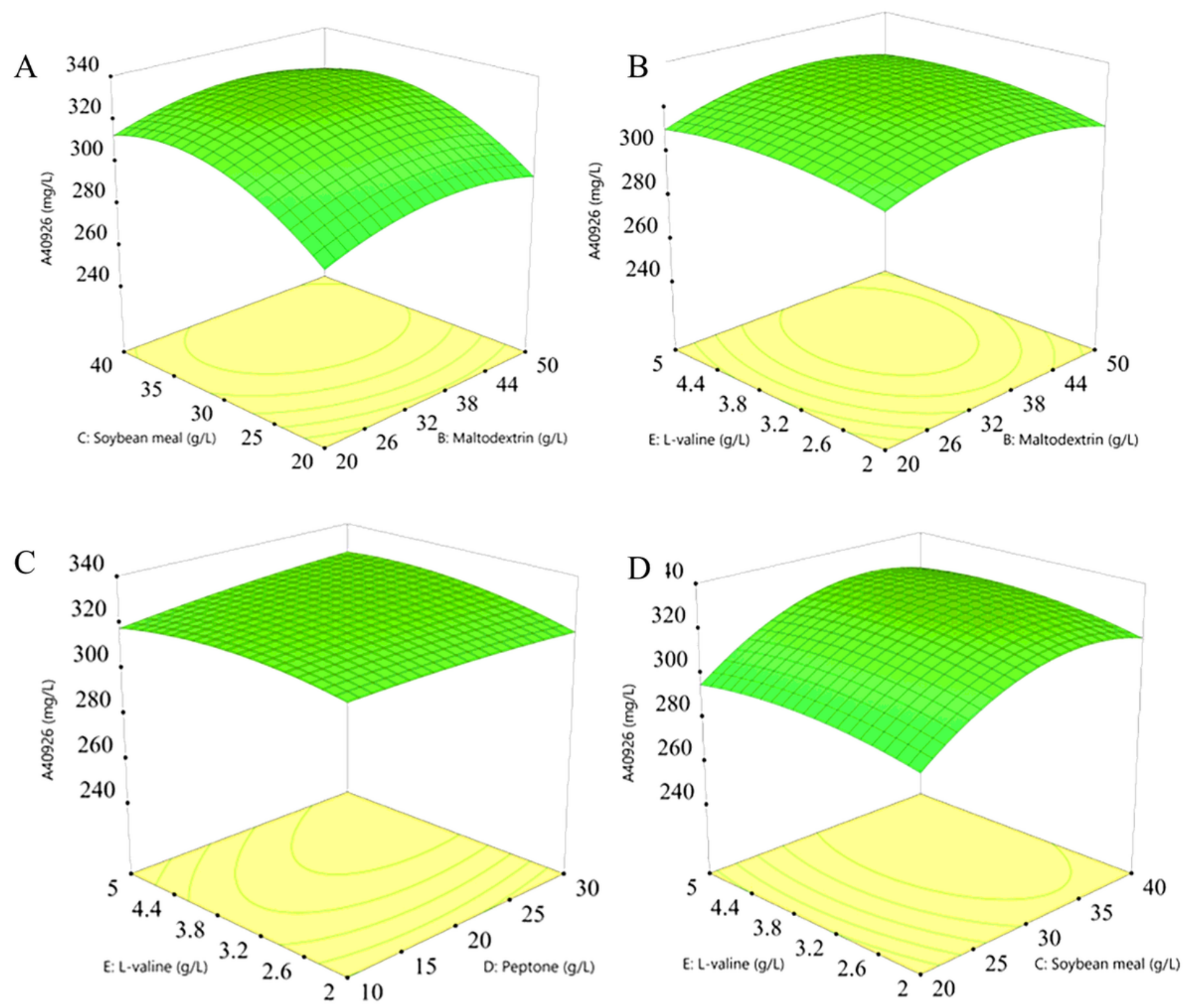

\section{Figure 4}

Three-dimensional response surface curves for A40926 production yield presenting the mutual interactions of independent variables. (A) soybean meal and maltodextrin; (B) L-valine and maltodextrin; (C) L-valine and peptone; (D) L-valine and soybean meal. 


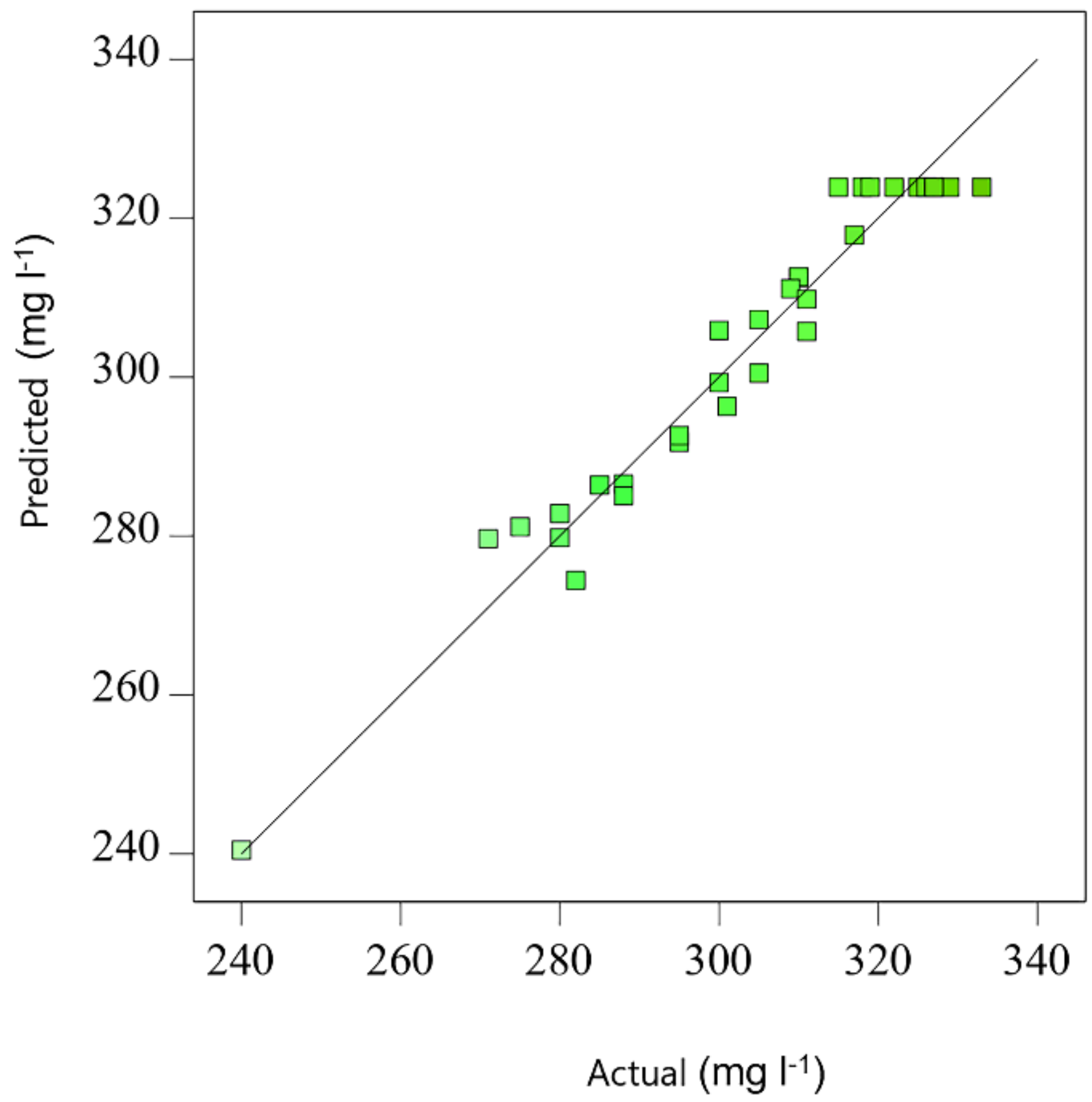

Figure 5

Correlation of predicted values versus experimental values of the response surface methodological model developed by central composite design. 


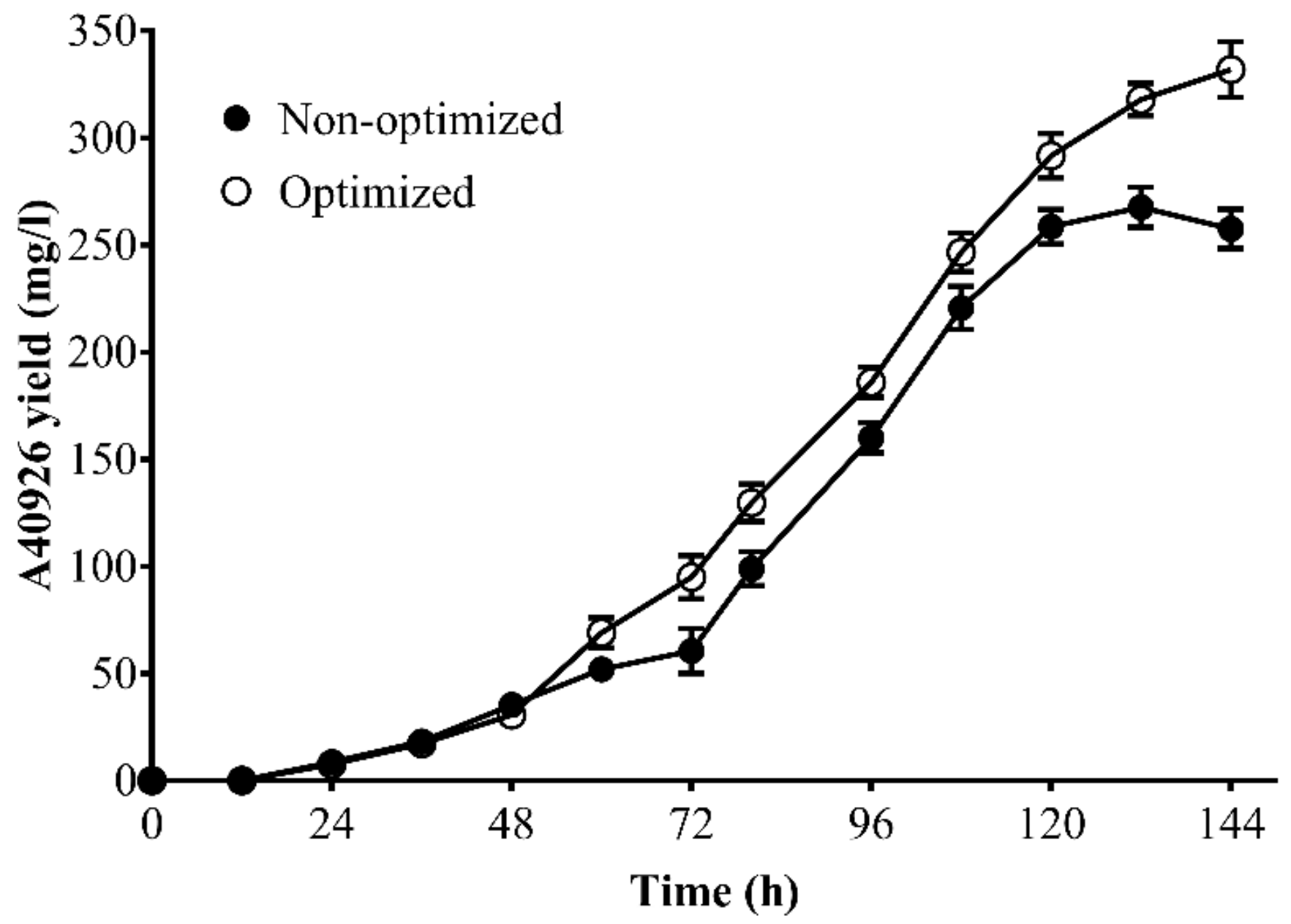

Figure 6

Fermentation profiles of A40926 production in shake flask experiments using the optimized media.

\section{Supplementary Files}

This is a list of supplementary files associated with this preprint. Click to download.

- Supportinginformation.docx 